\title{
Filtration of Submicron Soot Particles, Oil Droplets, and their Mixtures on Single- and Multi-layer Fibrous Filters
}

\author{
Mateusz Kamiński ${ }^{1}$, Jakub M. Gac ${ }^{1}$, Piotr Sobiech², Paweł Kozikowski², \\ Szymon Jakubiak ${ }^{2}$, Tomasz Jankowski \\ ${ }^{1}$ Faculty of Chemical and Process Engineering, Warsaw University of Technology, 00-645 \\ Warsaw, Poland \\ ${ }^{2}$ Central Institute for Labour Protection - National Research Institute, 00-701 Warsaw, Poland
}

\begin{abstract}
The dynamics of filtration efficiency and pressure drop during the simultaneous filtration of soot and oil aerosols on single- and multi-layer filters were investigated, and the determined filtration efficiency was compared with the theoretical efficiency obtained via the classical filtration theory. Additionally, the influence of liquid-phase aerosols on the morphology of the formed deposits was investigated. It was concluded that the addition of oil aerosols decreased the filtration efficiency and lowered the pressure drop increase rate for multi-layer filters. Additionally, for the filtration of aerosols containing soot and high oil concentrations, once maximum filtration efficiency was reached, an efficiency decrease occurred. The system imperfection factor was proposed as a mean to predict the efficiency of multi-layer filters. The modified version of the single fibre efficiency method was used to calculate filter mass change with reasonable accuracy.
\end{abstract}

Keywords: Fibrous filters, Filtration dynamics, Filtration efficiency, Mixed aerosols, Submicron aerosols

\section{OPEN ACCESS}

Received: September 29, 2021

Revised: February 4, 2022

Accepted: February 7, 2022

${ }^{*}$ Corresponding Author:

Mateusz.Kaminski.dokt@pw.edu.pl

\section{Publisher:}

Taiwan Association for Aerosol Research

ISSN: $1680-8584$ print

ISSN: 2071-1409 online

Copyright: The Author(s). This is an open access article distributed under the terms of the Creative Commons Attribution License (CC BY 4.0), which permits unrestricted use, distribution, and reproduction in any medium, provided the original author and source are cited.

\section{INTRODUCTION}

Fibrous filters are widely utilised in industrial (Agranovski and Braddock, 1998a, b), health (González et al., 2016; Praphawatvet et al., 2020; Sutherland, 2008) and other applications, such as heating, ventilation, and air conditioning installations (HVAC) (González et al., 2016). Fibrous filters have been thoroughly studied due to their common utilisation in removing solid and liquid particles suspended in gases and are continuously studied due to constant filter performance requirement revisions, filter adaptation for new applications, and overcoming filter limitations. The filtration process of solid particles from a gas stream utilising nonwoven filters is well established. The classical filtration theory (CFT), developed based on experimental results and theoretical concepts, allows the prediction and understanding of filtration efficiency dependence on particle diameter and filter morphology (Lee and Liu, 1982, 1981). The previous studies provided a description of the evolution of filtration efficiency and pressure drop during the filtration process (Thomas et al., 1999).

According to the CFT, the initial filtration efficiencies of liquid and spherical solid particles can be described the same way (Agranovski and Braddock, 1998a, b; Contal et al., 2004); however, the dynamics of the liquid droplet and solid particle filtration differ significantly because the droplets deposited on the filtration fibres form a liquid film or liquid bridges instead of the characteristic dendrite-like deposits formed by solid particles (Contal et al., 2004). Multiple studies determined that the exact behaviour of a system during filter loading with liquid depends on various factors such as fibre wettability, change in fibre diameter during filtration, packing density, and surface area changes due to the different ways droplets can attach to the fibres (Contal et al., 2004). 
They also considered factors such as the kinetics of the collision between the droplet and the fibre and fibre/surface properties (Gac and Gradoń, 2012, 2011). These studies provide a theoretical description of the evolution of liquid droplet filtration on fibrous filters and have improved the description of the pressure drop dynamics during mist filtration (Gac, 2015). These theoretical results concur with the experimental results. Despite this significant progress, numerous uncertainties remain, such as the evolution of efficiency and pressure drop during filter loading with liquid aerosol, the simultaneous filtration of solid and liquid particles, phobic systems, entrainment, and secondary aerosol generation (Mead-Hunter et al., 2014).

The logical continuation to investigation on single-phase aerosol filtration was the consideration of solid-liquid mixture aerosol filtration. Previous studies have been performed on the influence of trapped liquid in the filter structure on solid particle filtration and vice versa. Müller et al. (2014) investigated the pre-coating of filtration fibres with oil to improve dust filtration efficiency, whereas Mead-Hunter et al. (2012) studied the influence of deposited soot particles on oil mist filtration in fibrous filters. Another work on this subject is the paper by Boskovic et al. (2007) where the filtration of solid nanoparticles of different size on oil coated fibres has been considered. The authors found that after coating of fibres with oil the filter performance characteristics became similar for all particle shapes. The reason was that the oil coating minimizes the amount of particle motion along the fibre after the initial collision. Other studies investigated the consecutive filtration of solid and liquid aerosols (Gac et al., 2018, 2016) to determine the influence of solid deposits on droplet filtration and the morphology reorganisation of these deposits during filtration. It has been proven that liquid aerosol addition results in lower efficiency in the consecutive filtration of solid and liquid particles because liquid droplets destroy the dendrite-like structures, and the liquid deposited on the fibres prevents their formation (Gac et al., 2016). The origin of destruction (collapse) of dendritic structures by addition of liquids during or before deposition of solid particles has been first proposed by Müller et al. (2014). The full numerical model of this phenomenon was presented in details in our previous work (Gac et al., 2018). We have shown that in the presence of liquid film during the aerosol deposition, additional interactions between solid particles appear, which build the agglomerate. These interactions are: Capillary forces that act between solid particles trapped on the surface of liquid or immersed liquid film (Kralchevsky et al., 1995) and liquid bridging forces which result from the presence of so-called "liquid bridges" between solid particles. When solid particles are close enough but do not touch each other and are connected by a liquid bridge, the surface tension of liquid acts on the solid particles (Lian et al., 1993). In the paper (Gac et al., 2018) numerical simulations have been carried which allowed to track the change in the structure of agglomerates. The obtained results are consistent with scanning electron microscopy (SEM) observations.

Some of the above-mentioned results apply to the filtration of solid-liquid aerosol mixtures; however, these processes have been minimally investigated. Frising et al. (2004) analysed the evolution of pressure drop during mixed aerosol filtration, and our previous study (Kamiński et al., 2020) provided insight into the influence of water droplets in gas on the filtration of solid particles and the morphology of deposits. However, advanced studies and data on efficiency and pressure drop that allow easy comparison and validation of the results, e.g., complex systems involving both solid and liquid aerosols (Mead-Hunter et al., 2014), have not yet been performed.

This study investigates the dynamics of the simultaneous filtration of solid and liquid nanoparticles on fibrous filters and focuses on the evolution of filtration efficiency and pressure drop caused by particle deposition on the fibres. The results show the effect of the dendrite-like structure formation on the surface of the fibres on the efficiency and pressure drop and the effect of the addition of oil (di-ethylhexyl-sebacate, DEHS) on their initial values and evolution. Solid particles are represented by soot due to its similarity to diesel soot, one of the most common air pollutants (Löffler, 2004). The liquid particle aerosol was produced utilising DEHS due to its fibre wetting ability, which complements our previous study that utilised water (Kamiński et al., 2020).

\section{MATERIALS AND METHODS}

\subsection{Filters}

The filters utilised in the experiments were made of polypropylene via the melt-blown technique. 
Table 1. Properties of layers utilised in the experiments.

\begin{tabular}{llll}
\hline Filtration layer & Mean fibre diameter $(\mu \mathrm{m})$ & Layer thickness $(\mathrm{mm})$ & Packing density $(-)$ \\
\hline F1 & $1.38 \pm 0.89$ & $2.128 \pm 0.073$ & $0.035 \pm 0.001$ \\
2F1 & & $3.733 \pm 0.137$ & $0.031 \pm 0.001$ \\
F6 & $6.67 \pm 4.24$ & $0.878 \pm 0.089$ & $0.127 \pm 0.012$ \\
2F6 & $2.050 \pm 0.089$ & $0.115 \pm 0.005$ \\
F13 & $13.24 \pm 7.53$ & $0.969 \pm 0.050$ & $0.182 \pm 0.009$ \\
2F13 & & $1.291 \pm 0.062$ & $0.246 \pm 0.012$ \\
\hline
\end{tabular}

The layers are named after their mean fibre diameters, as listed in Table 1, and layer names beginning with " 2 " indicate layers with higher thicknesses but do not mean the layer is twice as thick. The diameters of the fibres were determined from images of fibres taken using a scanning electron microscope (HITACHI SU8010). The thickness of the layers was measured utilising mechanical contact method thickness tester (Tilmet 79). The thickness of the layers, their mass and the density of the material, were used to calculate the packing density.

The layers listed in Table 1 and their different combinations (e.g., F6/F13 and F13/2F6) were experimentally tested; however, layers F1 and 2F1 were not utilized in the multi-layer systems due to their high initial efficiencies, which prevents measurable changes in efficiency over time.

\subsection{Experimental Setup}

Filtration efficiency and pressure drop measurements were performed utilising the experimental setup presented in Fig. 1. The principal component of the setup is a horizontal stainless steel duct with an inner diameter of $80 \mathrm{~mm}$, which has one inlet for the test aerosol: soot particle or oil droplet (di-ethyl-hexyl-sebacate, DEHS) aerosol, or mixtures of these aerosols. The aerosols were diluted with purified air, and the composition of the test aerosol was controlled utilising valves and mass flow controllers. The filter holder was designed for flat filter media with an effective filtration area of $50 \mathrm{~cm}^{2}$, and the face velocity on the filter surface was $0.2 \mathrm{~m} \mathrm{~s}^{-1}$. The residence time of the aerosol in the system from its formation to contact with the filter was $10.9 \mathrm{~s}$. The purified air utilised for aerosol dilution was introduced at the central installation of compressed air and filtered via a filtered air supply 3074 B (TSI Inc., USA).

The soot particles were generated in an argon atmosphere utilising a GFG 1000 spark generator (Palas $\mathrm{GmbH}$, Germany). The argon volume flow rate was $5 \mathrm{dm}^{3} \mathrm{~min}^{-1}$, the spark frequency between the graphite electrodes during the experiment was $450 \mathrm{~Hz}$, and the graphite density was $2090 \mathrm{~kg} \mathrm{~m}^{-3}$.

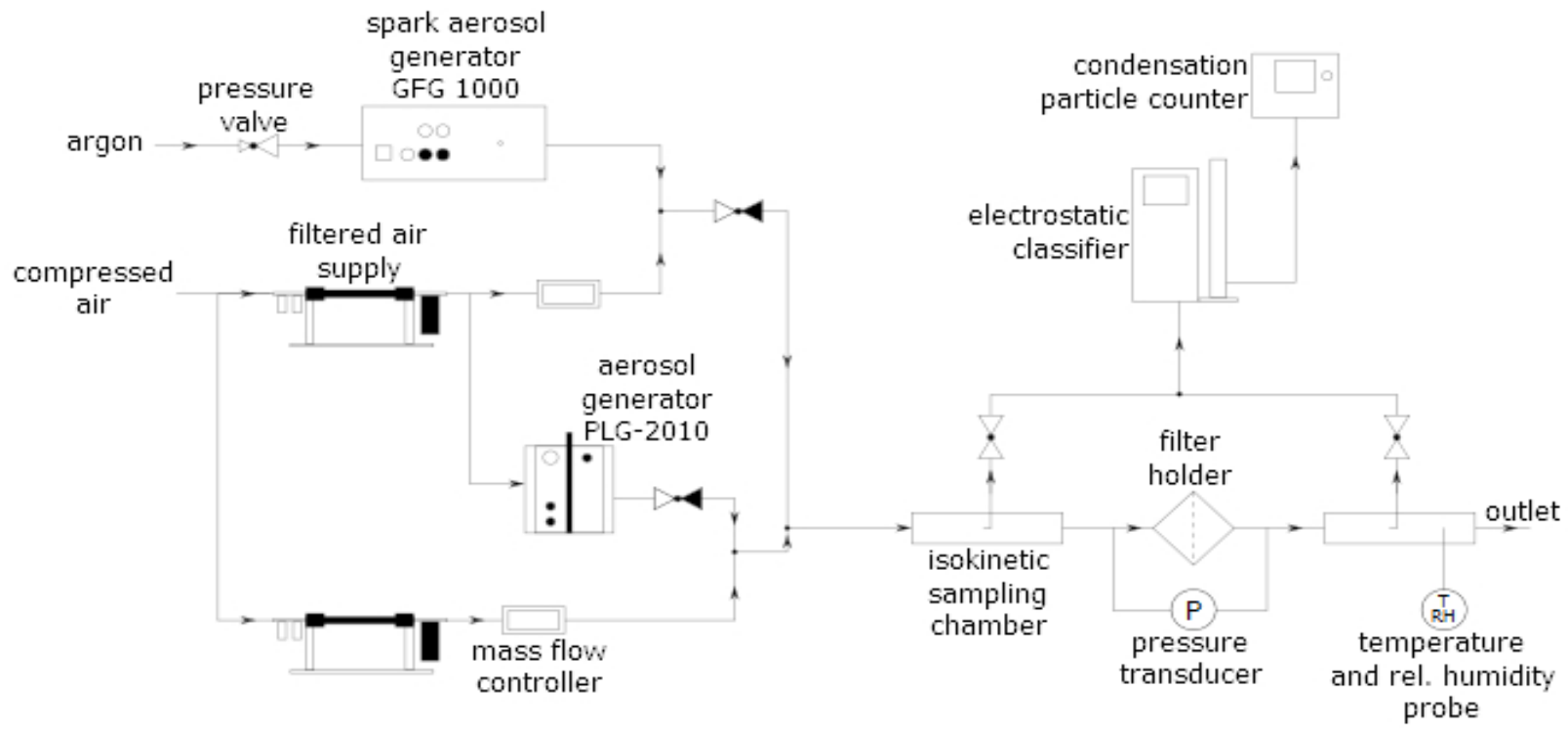

Fig. 1. Experimental setup utilised to investigate filter efficiency and pressure drop during aerosol particle filtration. 
Oil droplets were generated utilising a PLG-2010 generator (Palas GmbH, Germany). The oil density was $914 \mathrm{~kg} \mathrm{~m}^{-3}$, and generator pressures of 1 and 2 bar achieved for the flow of 14.3 and $22.7 \mathrm{dm}^{3} \mathrm{~min}^{-1}$ were utilized to produce the low- and high-concentration oil aerosols, respectively. Descriptions of the aerosols are provided in the following section.

The aerosol filtration efficiencies were determined based on the overall particle number concentrations downstream of the filter. These concentrations were measured utilising a scanning mobility particle sizer (SMPS) spectrometer (TSI Inc., USA) which enabled the measurement of the concentration of particles with sizes ranging from $32.2-735.6 \mathrm{~nm}$. It consist of an ultrafine condensation particle counter (UCPC 3776) and electrostatic classifier 3082 utilising a DMA 3081A. A P26 differential pressure transducer (Halstrup Walcher, Germany) was utilised to measure the pressure drop across the filters, and the temperature and relative humidity of the air downstream of the filter were measured utilising a thermo-hygrometer HP23-A (Rotronic, Switzerland). The temperature of aerosols was about $295 \mathrm{~K}$, and the relative humidity of air was about $5 \%$.

After loading with soot and oil particles, the fibres were observed utilising a HITACHI SU8010 high-resolution field emission scanning electron microscope. The samples were coated with gold utilising a Quorum Q150T ES sputter coater to increase the conductivity. Observations were conducted at acceleration voltages and magnifications of $10 \mathrm{kV}$ and $2000 \times$ (Fig. 4(a)), $5 \mathrm{kV}$ and $500 \times$ (Fig. 4(b)), and $2 \mathrm{kV}$ and 500× (Fig. 4(c)).

\subsection{Aerosols}

Five different aerosols were utilised in the experiments, soot aerosol, high- (oil_h) and low(oil_l) concentration oil aerosols. The authors decided to also investigate two mixture systems differing in liquid particles concentration (soot+oil_h, soot+oil_l). The main purpose of showing a series containing a lower oil concentration (soot+oil_l) is to draw attention to the lack of clearly visible maximum in the efficiency in this system. Comparison of the two mixture cases allows conclusions to be drawn about the effect of the amount of oil deposited on the fibres on the occurrence of this effect. The case of sole soot and sole oil aerosol is intended as a background for a more interesting mixture aerosol case allowing a comparison, using scanning electron microscopy, of the differences in the structure of the deposits on the filter fibres and their influence on filtration efficiency.

Total concentration, weighted arithmetic mean particle diameter, and their standard deviations were calculated based on 55 measurements of the soot and oil_h aerosols and 85 measurements of the other aerosols and are presented in Table 2. The total concentrations of the mixed aerosols are lower than the sum of their component aerosols due to the high particle concentration, resulting in particle interactions.

The size distributions of the aerosols are presented in Fig. 2. It can be seen that for oil_h aerosol the particle concentration for the cut-off size $(735.6 \mathrm{~nm})$ is significantly higher compared to the other aerosols.

An important issue is to determine whether the flow of mixed aerosol (soot particles and DEHS droplets) between the place where they are mixed and the filter where they are captured does not cause particles or droplets to merge with each other. To this end, we carried out aerosol distribution measurements (without the presence of a filter) for three lengths of the inlet pipe. For each of these lengths, we have determined the first three distribution moments, defined as follows:

$M_{k}=\int v^{k} n(v, t) d v$

These first three moments have a well-defined physical meaning. The moment $M_{0}=\int n(v, t) d v$

Table 2. Properties of the aerosols utilised in the experiments.

\begin{tabular}{llllll}
\hline Aerosol & soot & oil_h & soot+oil_h & oil_I & soot+oil_I \\
\hline Mean particle diameter $(\mathrm{nm})$ & 88.32 & 226.69 & 190.34 & 224.84 & 103.25 \\
Diameter standard deviation $(\mathrm{nm})$ & 56.18 & 138.11 & 141.88 & 145.78 & 78.69 \\
Total concentration $\left(\right.$ particles $\mathrm{cm}^{-3}$ ) & $8.64 \mathrm{E} 6$ & $8.89 \mathrm{E} 6$ & $12.82 \mathrm{E} 6$ & $0.77 \mathrm{E} 6$ & $9.39 \mathrm{E} 6$ \\
Concentration standard deviation $\left(\right.$ particles $\mathrm{cm}^{-3}$ ) & $0.07 \mathrm{E} 6$ & $0.16 \mathrm{E} 6$ & $0.12 \mathrm{E} 6$ & $0.05 \mathrm{E} 6$ & $0.06 \mathrm{E} 6$ \\
\hline
\end{tabular}



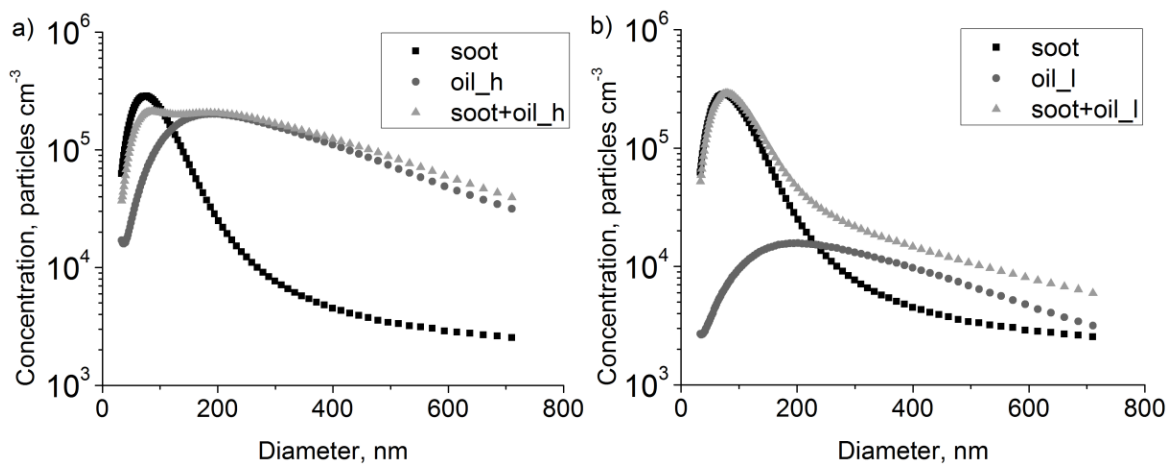

Fig. 2. Particle size distributions of generated (a) soot particles, high-concentration oil aerosol (oil_h), and their mixture (soot+oil_h), and (b) soot particles, low-concentration oil aerosol (oil_l), and their mixture (soot+oil_l)

is a total concentration of particles of any volume, the moment $M_{1}=\int v \cdot n(v, t) d v$ is a total volume of all the particles (per the volume of the system) and the moment $M_{2}$ is connected with mean particle volume by means of expression $\langle v\rangle=M_{2} / M_{1}$. This means that if there is agglomeration in the system, the zero moment should be decreasing, and the second moment - an increasing function of the inlet length. The values determined by us, however, did not confirm this tendency - hence the conclusion that the length of the aerosol inlet line does not play a significant role. The difference between the particle size distribution and total concentration of a mixed aerosol and the sum of the respective sole aerosols results from the agglomeration that occurs at the place where aerosols are mixed.

\subsection{CFT Calculations}

The filtration efficiency calculations were performed utilizing the single fibre efficiency method (see appendix A). For the calculations of later stages of filtration, the effect of loading the filters with deposits was taken into account. The volume of deposits affects the packing density, which leads to a change in average velocity in the filter and diameter of the fibres. In the case of solid particles, their effective density depends on their actual dimensional structure. The effective density for solid and mixture aerosols was calculated. Based on that, for each time step, the volume of deposits, the mass of deposits, packing density, average velocity, and fibre diameter was calculated (see appendix B). Based on these values, the new filtration efficiency was obtained, and all the calculations were repeated for the next time step. The total efficiency of the filter was calculated based on the fractional efficiency and the shares of individual fractions of particles in the aerosol (Fig. 2).

\section{RESULTS}

\subsection{Scanning Electron Microscopy}

Fig. 3(a) shows the hierarchical structure of the agglomerates formed on the surface of the fibres during soot aerosol filtration. Fig. 3(b) shows that the surfaces of the fibres are covered with oil during oil_h aerosol filtration and that oil is collected at the fibre connection and contact points. Some barrel-shaped droplets were observed on the smaller fibre surfaces. Fig. 3(c) shows that for mixed aerosol soot+oil_h, the comprehensive dendrite structure made of soot particles was not present, and the soot particles clustered together and were oil covered. The particle clusters may be the remnants of a residual structure formed in the initial filtration phase when the fibres are not yet uniformly coated with oil. Similar to oil_h aerosol filtration, the fibres and their junction points were covered in oil.

\subsection{Single-layer Filters}

Fig. 4 presents the efficiency changes of the single-layer filters during loading. Each measurement period was $64 \mathrm{~min}$, and the first $4 \mathrm{~min}$ were omitted due to reading instability during this period. 


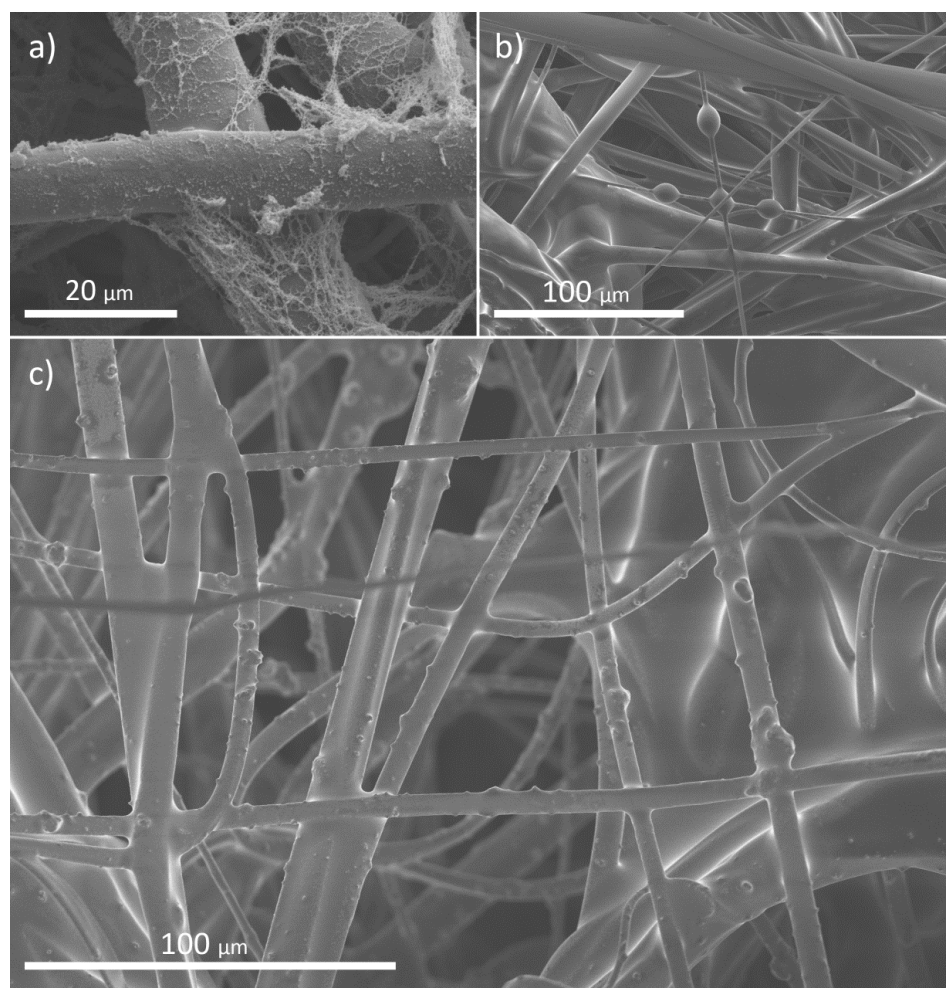

Fig. 3. Scanning electron microscope images of filtration deposits formed during (a) soot aerosol, (b) oil_h aerosol, and (c) soot+oil_h mixture filtration.

The lowest efficiency for all the filters occurred utilizing oil_h aerosol, followed by the soot+oil_h aerosol. The second-highest efficiency occurred utilizing the soot+oil_I aerosol, and the highest efficiency occurred utilizing the soot aerosol, except for filters F13 and F1, where the last two are in reverse order. For the soot+oil_h aerosol, there is an evident efficiency increase until the maximum efficiency is reached, after which the efficiency decreases or stabilizes. The efficiency of the oil_h aerosol was constant for the measurement period, except when utilized on the highefficiency filters (F1 and 2F1), where the efficiency significantly decreases. A lower oil concentration does not drastically change the efficiency (particularly initial efficiencies for the soot and soot+oil_l aerosols are nearly equal for all the filters). However, a higher oil concentration results in an obvious efficiency decrease, attributed to the particles sliding on the fibres covered with a thin oil layer, which similarly occurs with the oil_h aerosol. This effect is more evident with higher oil concentrations.

Evident maximum efficiencies and significantly greater mass change (Section 3.5) occurred during soot+oil_h and oil_h aerosol filtration. The stage of coalescence was reached utilizing high-efficiency filters F1 (Fig. 4(e)) and 2F1 (Fig. 4(f)) for the filtration of oil_h aerosol, which decreased the filtration surface area which concurs with previous study results (Charvet and Thomas, 2017). The addition of soot produced maximum efficiency. This study determined that the initial efficiency increase was attributed to the increased efficiency of liquid (oil) particle filtration due to the presence of solid (soot) particles. The solid particles and hierarchical solid structures created additional surface areas for the adherence of the oil droplets. It can be expected that when maximum efficiency was reached, the filter was clogged with liquid and solid particles, causing deposit reorganisation (due to the presence of liquid bridges), increased particle velocity (due to reduced flow area), and entrainment (due to fibres reaching maximum capacity for particle attachment). It could explain the efficiency decrease that occurred after maximum efficiency was reached. This phenomenon is more evident for filters F1 and 2F1 than for filters 2F13 and 2F6 (Figs. 4(e), 4(f), 4(b), and 4(d), respectively), and this effect was more pronounced as the overall filter efficiency increased.

Fig. 5(a) shows the pressure drop change as a percentage of the initial value for filter F13 during the filtration of all the aerosols. It shows typical behaviour for filters $2 \mathrm{~F} 13, \mathrm{F6}, 2 \mathrm{F6}$. Fig. $5(\mathrm{~b})$ shows 

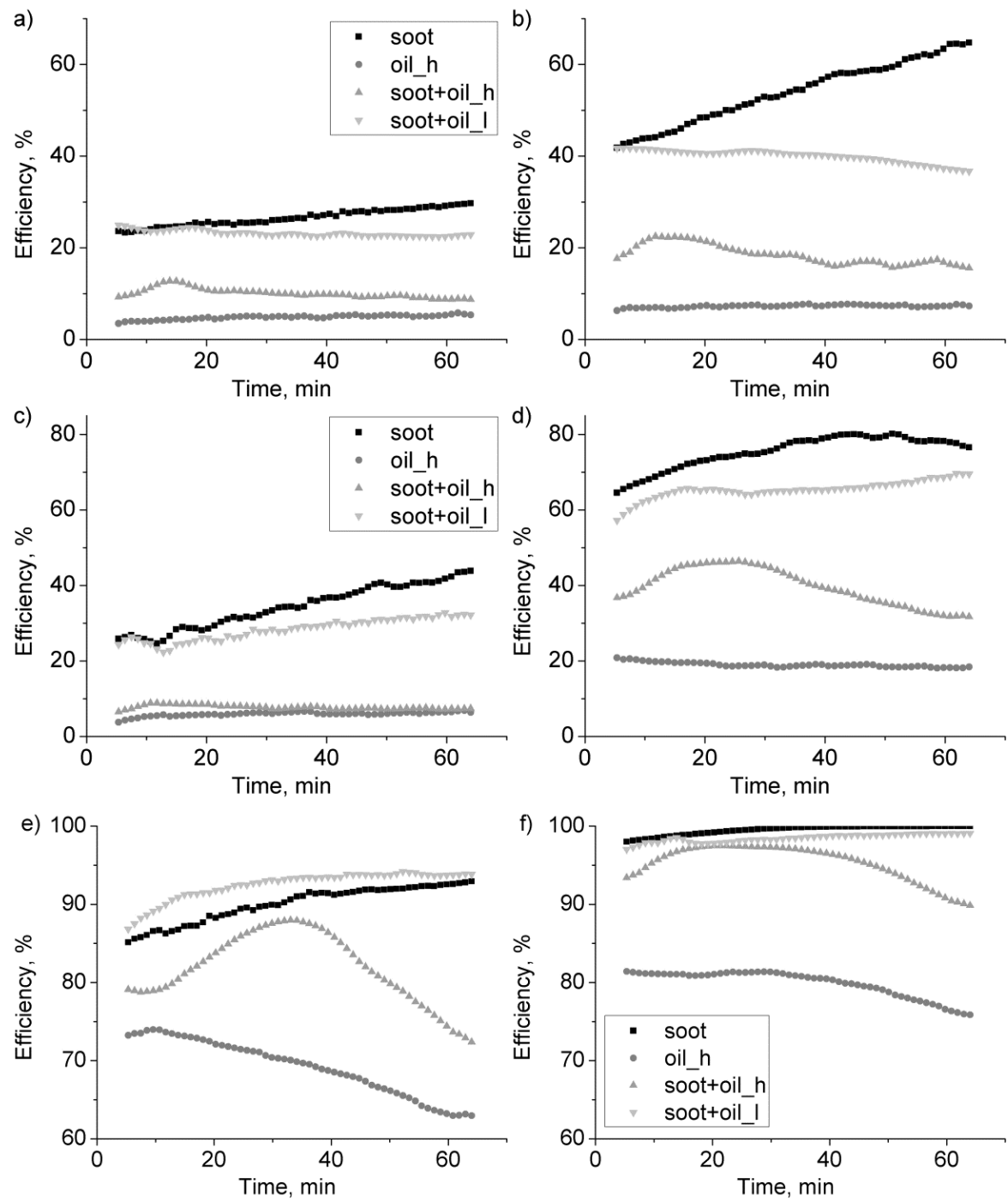

Fig. 4. Efficiency evolution for filters (a) F13, (b) 2F13, (c) F6, (d) 2F6, (e) F1, and (f) $2 F 1$.

the pressure drop evolutions during soot aerosol filtration and the evident pressure drop increases for all the filters. Moreover, the addition of oil prevents the pressure drop from increasing to the same extent as that of soot aerosol. Figs. 5(c) and 5(d) show that the pressure drop increases for filters F1 and 2F1, attributed to their high efficiencies, causing them to become clogged by oil. This explains why the pressure drop change is lower when utilizing soot+oil_l aerosol, which destroys the solid structure on the fibres, but the concentration is not high enough to clog the filter.

Table 3 presents the measured and calculated initial stage efficiencies. The soot aerosol values have the highest correlation except for filter 2F6. The addition of oil aerosol significantly increases the difference, and the CFT overestimates the efficiency in cases when a high amount of oil is present in the system. The largest difference was observed for the oil_h aerosol.

To quantify the difference between the calculated efficiency using CFT and those measured a coefficient will be introduced describing the difference. We will call it the system imperfection factor (SIF). The expression defining the SIF is as follow:

$E_{\text {measured }}=S I F \cdot E_{C F T}$

where $E_{\text {measured }}$ and $E_{C F T}$ denote the efficiency of the filter measured and computed utilizing CFT, respectively. It is expected that for filters and systems that meet CFT assumptions SIF is close to one, while when these assumptions, are not met - it can take any positive numbers. Table 3 shows the derived SIF values for single-layer filters and various systems. 

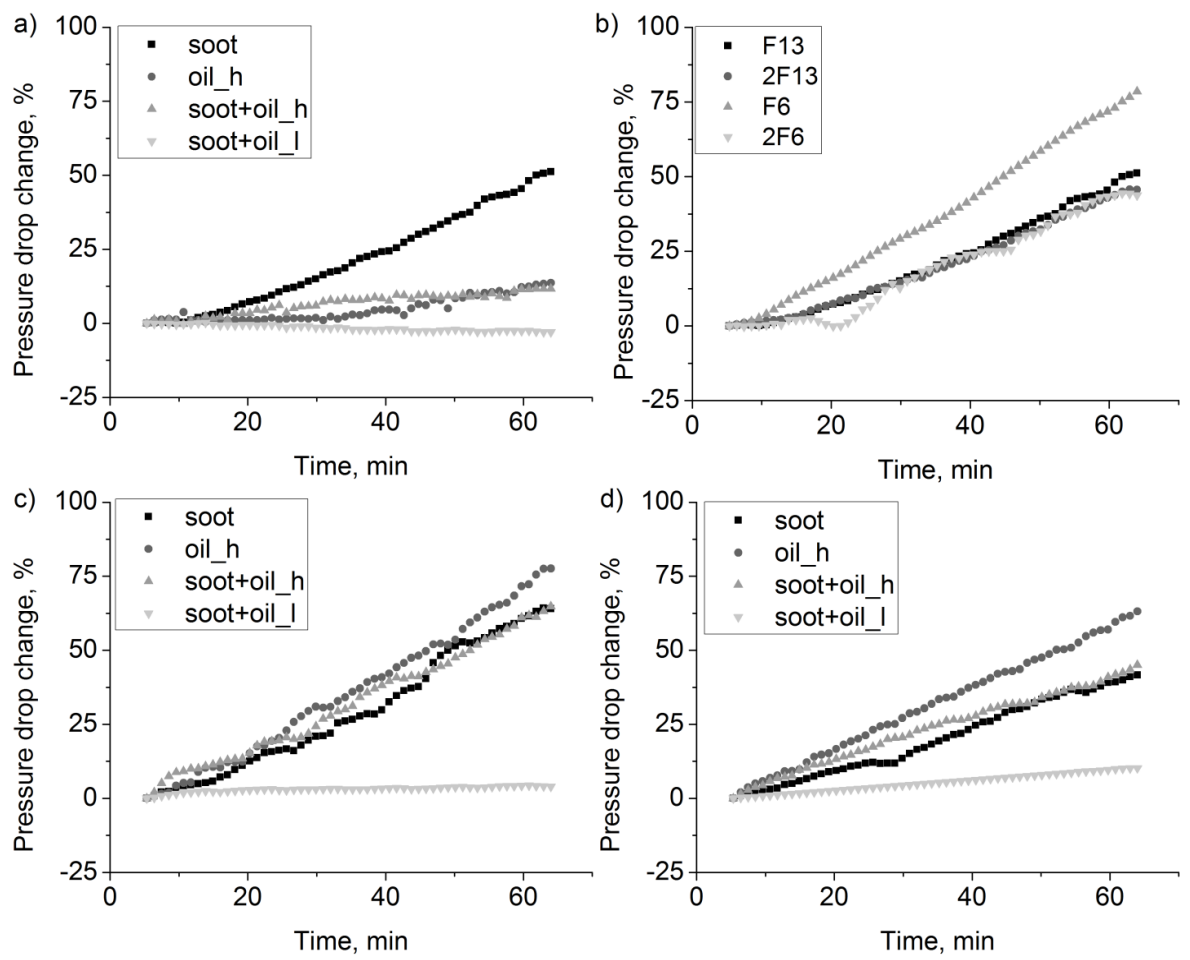

Fig. 5. Pressure drop evolution for filter (a) F13, (c) F1, (d) $2 F 1$ during the filtration of different aerosols and (b) pressure drop evolution comparison for filters F13, 2F13, F6, and 2F6 during soot aerosol filtration.

Table 3. Efficiency comparison between calculated and measured initial stage efficiencies for single-layer filters and values of system imperfection factor.

\begin{tabular}{|c|c|c|c|c|c|c|c|c|c|c|c|c|}
\hline Aerosol & \multicolumn{3}{|c|}{ soot } & \multicolumn{3}{|c|}{ oil_h } & \multicolumn{3}{|c|}{ soot+oil_h } & \multicolumn{3}{|c|}{ soot+oil_I } \\
\hline Filter & $\begin{array}{l}\text { measured } \\
(\%)\end{array}$ & $\begin{array}{l}\text { CFT } \\
\text { (\%) }\end{array}$ & $\begin{array}{l}\text { SIF } \\
(-)\end{array}$ & $\begin{array}{l}\text { measured } \\
(\%)\end{array}$ & $\begin{array}{l}\text { CFT } \\
\text { (\%) }\end{array}$ & $\begin{array}{l}\text { SIF } \\
(-)\end{array}$ & $\begin{array}{l}\text { measured } \\
(\%)\end{array}$ & $\begin{array}{l}\text { CFT } \\
(\%)\end{array}$ & $\begin{array}{l}\text { SIF } \\
(-)\end{array}$ & $\begin{array}{l}\text { measured } \\
(\%)\end{array}$ & $\begin{array}{l}\text { CFT } \\
(\%)\end{array}$ & $\begin{array}{l}\text { SIF } \\
(-)\end{array}$ \\
\hline F1 & 85.5 & 96.5 & 0.89 & 73.4 & 97.7 & 0.75 & 78.9 & 97.1 & 0.81 & 87.5 & 96.6 & 0.91 \\
\hline $2 \mathrm{~F} 1$ & 98.1 & 99.3 & 0.99 & 81.3 & 99.5 & 0.82 & 93.7 & 99.4 & 0.94 & 97.3 & 99.3 & 0.98 \\
\hline F6 & 26.3 & 34.5 & 0.76 & 4.2 & 35.5 & 0.12 & 7.0 & 35.0 & 0.20 & 25.4 & 34.7 & 0.73 \\
\hline $2 \mathrm{~F} 6$ & 65.4 & 61.0 & 1.07 & 20.6 & 59.0 & 0.35 & 37.1 & 60.0 & 0.62 & 58.7 & 60.9 & 0.96 \\
\hline $\mathrm{F} 13$ & 22.0 & 21.4 & 1.03 & 3.8 & 17.9 & 0.21 & 9.5 & 19.6 & 0.48 & 24.7 & 21.1 & 1.17 \\
\hline $2 F 13$ & 42.5 & 40.9 & 1.04 & 6.7 & 37.9 & 0.18 & 18.4 & 39.4 & 0.47 & 41.4 & 40.8 & 1.01 \\
\hline
\end{tabular}

As has been expected, for soot filtration the values of SIF are close to 1 for every filter and are in the range from 0.76 to 1.07 . Also for filtration of mixture soot+oil_I the values of SIF are close to one (between 0.73 and 1.17). For filtration of oil_h and soot+oil_h the values of SIF are smaller than one. For F1 and 2F1 filters, these values are still relatively close to 1 while for the remaining filters - much lower, ranging from 0.12 to 0.62 . The comparison of these values allows us to conclude that CFT describes the efficiency of the filter with good accuracy in the case of filtration of solid particles (possibly with a small admixture of liquid particles). CFT also describes well the filtration efficiency on filters with the thinnest fibres, regardless of aerosol type. On the other hand, in the case of filters with coarser fibres and a high content of liquid aerosol, this method breaks down.

\subsection{Multi-layer Filters}

Fig. 6 presents the efficiency changes of the multi-layer filters during filtration, and the "*" symbol denotes the first filter layer. The obtained results were similar to those of the single-layer filters. The highest filtration efficiency for all the filters was obtained utilizing soot aerosol. 

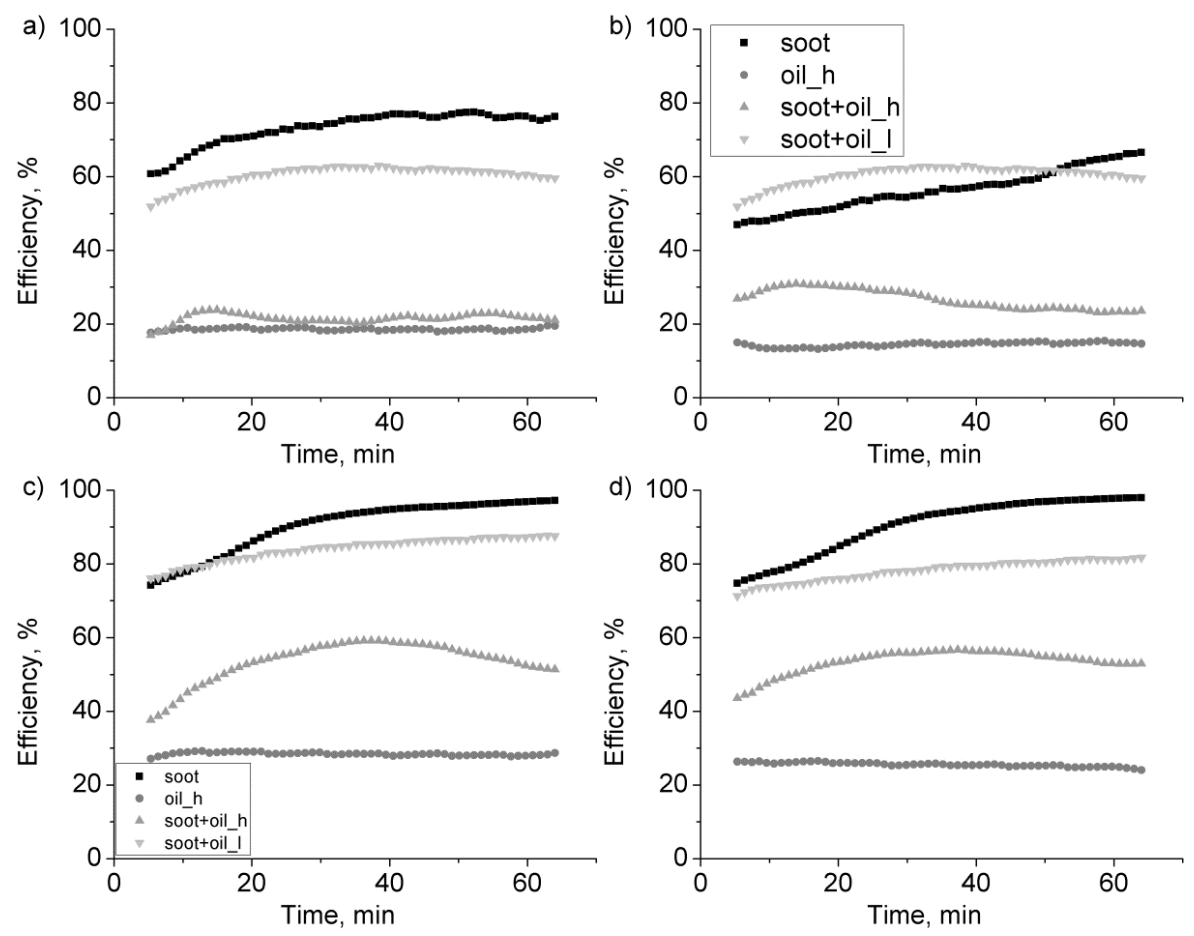

Fig. 6. Efficiency evolutions of filters (a) F6/F13*, (b) F6*/F13, (c) F13*/2F6, and (d) F13/2F6*.

The second-highest efficiency was obtained utilizing soot+oil_I aerosol for all the filters except filter F6*/F13, where the efficiency for soot was higher than for soot+oil_l just in the late stage of filtration. The third highest and the lowest efficiencies were obtained utilizing the soot+oil_h and oil_h aerosols, respectively. For the soot+oil_h aerosol, there is an evident maximum efficiency, after which the efficiency decreased or remained constant, and the efficiencies of all the filters utilising oil_h aerosol remained constant for the entire measurement period. Greater efficiency increases were observed utilizing soot and soot+oil_l aerosols with the multi-layer filters than with the single-layer filters.

A comparison of the efficiencies for the same multi-layer filters but with the layer order reversed shows that for both filters F13/2F6, there is no impact on efficiency due to the filter order. For filter F6/F13, the initial efficiency for soot was higher when F13 was the first filter, although a greater overall increase in efficiency was achieved when F6 was the first filter. A larger efficiency difference between the oil_h and soot+oil_h aerosols was observed for filter F6/F13 when F6 was the first filter. It can be attributed to the oil droplets sliding on the wetted fibres. When present in the system, soot helps capture the oil droplets, and because filter F6 has a higher efficiency towards soot than filter F13, a greater efficiency was achieved when filter F6 was the first layer.

Fig. 7(a) presents the pressure drop evolution of filter F6/F13* for four aerosols. The greatest pressure drop increase occurred utilizing soot aerosol, and for the aerosols containing oil, the pressure drop was significantly less or negligible than that of the soot aerosol. Like the singlelayer filters, the addition of oil in the system significantly impacts the pressure drop evolution and produces a smaller pressure drop change.

A comparison of the pressure drop for the same multi-layer filters but with the order of the layers reversed shows that for filters F6/F13 and F13/2F6, there is no evident impact of the filter order on the pressure drop change during filtration of the oil-containing aerosols. It is evident from Fig. 7(b) that the only impact of the filter order was the filtration of soot aerosol by filter F6/F13, where a larger pressure drop change occurred when filter F13 was the first layer compared with F6 as the first layer. Although both layers had similar initial efficiencies (Figs. 4(a) and $4(\mathrm{c})$ ), the higher packing density of filter F13 (Table 1) results in a more dynamic filling of the open spaces due to the expansion of the solid structure.

The pressure drop for all the single- and multi-layer filters increased during the filtration of soot aerosols due to the formation of a hierarchical structure on the surface of the fibres (Fig. 3(a)), 

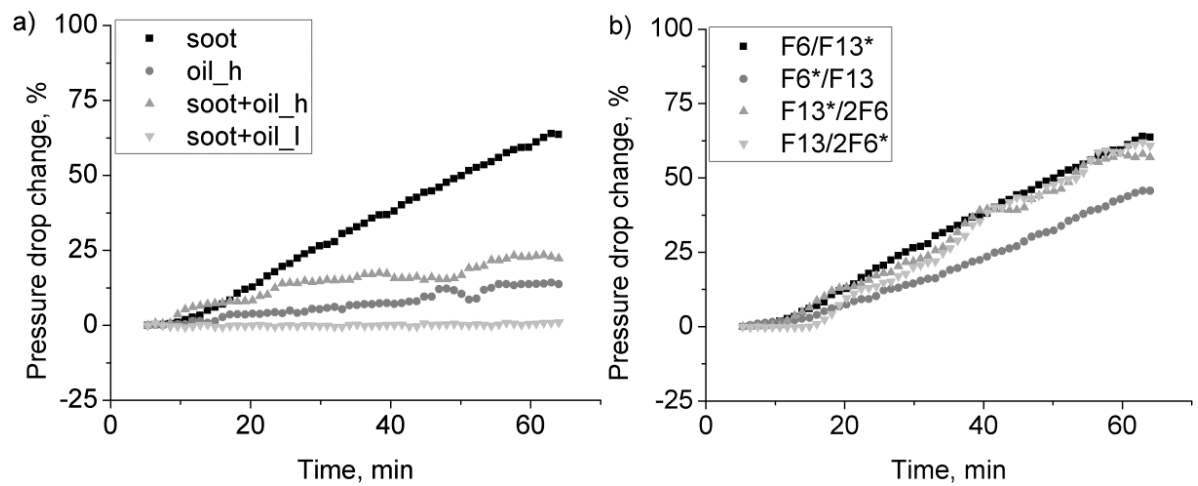

Fig. 7. (a) Pressure drop evolution for filter F6/F13* during the filtration of different aerosols and (b) comparison of the pressure drop evolution for filters F6/F13*, F6*/F13, F13*/2F6, and F13/2F6* during the filtration of soot aerosol.

which also increased the filtration efficiency. However, the presence of oil in the aerosol prevents soot structure formation (Fig. 3(c)), and consequently, the pressure drop does not change significantly, except for the highly efficient filters (F1 and 2F1). For the highly efficient filters (F1 and 2F1), the observed pressure drop increases were attributed to the filters becoming clogged with oil and soot particles, which also correlate with their mass changes, as shown in Fig. 8. Müller et al. (2014) determined that consecutive filtration of solid and liquid aerosols destroys the solid structure until the remaining areas are fully covered in liquid. For consecutive filtration of liquid and solid aerosols, the solid particles penetrate deep into the liquid film, creating a structure inside the film, and when the film capacity for solid particles is exhausted, the structure is built outside the film. However, this phenomenon was not observed in this study, even though the mass changes for the mixed aerosols were greater than that for the oil aerosols (Section 3.5). Simultaneous filtration of solid and liquid particles did not lead to solid structure formation because the constant collisions between the new particles captured from the aerosol stream and those already deposited on the fibres prevented structure formation.

Contrary to the results obtained by Mead-Hunter et al. 2012), the results of this study indicate that the presence of solid particles in a film formed on the surface of the fibres does not result in an increased pressure drop. This may be due to the formation of agglomerates in the oil captured on the fibres (Fig. 3(c)), which prevented solid particles from being evenly distributed in the oil film.

\subsection{Multi-layer Filters Efficiency Calculations Utilising System Imperfection Factor}

Table 4 compares the calculated and measured initial stage efficiencies for the multi-layer filters. Similar to the calculations for the single-layer filters, the theoretically expected efficiencies for the multi-layer filters were calculated utilizing the CFT as a product of the efficiencies of the respective layers assuming they perform independently, i.e.:

$P_{\text {filter }}=P_{\text {layer } 1, C F T} \cdot P_{\text {layer } 2, \text { CFT }}$

Table 4. Efficiency comparison between calculated and measured initial stage efficiencies for multi-layer filters.

\begin{tabular}{|c|c|c|c|c|c|c|c|c|c|c|c|c|}
\hline Aerosol & \multicolumn{3}{|c|}{ soot } & \multicolumn{3}{|c|}{ oil_h } & \multicolumn{3}{|c|}{ soot+oil_h } & \multicolumn{3}{|c|}{ soot+oil_I } \\
\hline Filter & $\begin{array}{l}\text { measured } \\
\text { (\%) }\end{array}$ & $\begin{array}{l}\text { CFT } \\
(\%)\end{array}$ & $\begin{array}{l}\text { CFT-SIF } \\
(\%)\end{array}$ & $\begin{array}{l}\text { measured } \\
(\%)\end{array}$ & $\begin{array}{l}\text { CFT } \\
(\%)\end{array}$ & $\begin{array}{l}\text { CFT-SIF } \\
(\%)\end{array}$ & $\begin{array}{l}\text { measured } \\
(\%)\end{array}$ & $\begin{array}{l}\text { CFT } \\
(\%)\end{array}$ & $\begin{array}{l}\text { CFT-SIF } \\
(\%)\end{array}$ & $\begin{array}{l}\text { measured } \\
\text { (\%) }\end{array}$ & $\begin{array}{l}\text { CFT } \\
(\%)\end{array}$ & $\begin{array}{l}\text { CFT-SIF } \\
\text { (\%) }\end{array}$ \\
\hline F6/F13* & 61.0 & 48.5 & 42.5 & 17.9 & 47.1 & 7.9 & 17.7 & 47.8 & 15.8 & 53.0 & 48.5 & 48.9 \\
\hline F6*/F13 & 47.4 & & & 14.5 & & & 27.2 & & & 53.3 & & \\
\hline 2F6/F13* & 75.1 & 69.3 & 73.0 & 27.6 & 66.3 & 23.6 & 38.7 & 67.8 & 43.1 & 76.4 & 69.2 & 71.7 \\
\hline $2 \mathrm{~F} 6 * / \mathrm{F} 13$ & 75.5 & & & 26.3 & & & 44.3 & & & 72.2 & & \\
\hline
\end{tabular}

CFT: classical filtration theory; CFT-SIF: classical filtration theory modified with SIF. 
$E_{\text {filter }}=100-P_{\text {filter }}=100-\left(100-E_{\text {layer } 1, \text { CFT }}\right) \cdot\left(100-E_{\text {layer2,CFT }}\right) / 100$

where $P_{\text {filter }}$ and $E_{\text {filter }}$ are, respectively, penetration and efficiency of the multi-layer filter and $P_{\text {layer1,CFT }}$ and $E_{\text {layer1,CFT }}$ are the same quantities calculated for single layer utilizing CFT.

For the multi-layer filters, similar to the single-layer filters, relative differences for soot aerosol are low, and like for the single-layer filters, the addition of high concentration oil aerosol greatly increases the relative difference. The CFT overestimated efficiencies in all cases where a high amount of oil was present in the system and underestimated where a low amount of oil was present in the system.

We may improve the agreement between experimental and computational efficiency by replacement of Eq. (4) with the following equation, containing SIF coefficients, which have been introduced in the previous section Eq. (2):

$E_{\text {filter }}=100-\left(100-S I F_{\text {layer } 1} \cdot E_{\text {layer1,CFT }}\right) \cdot\left(100-S I F_{\text {layer2 } 2} \cdot E_{\text {layer2,CFT }}\right) / 100$

Results of calculations are presented in Table 4.

By analysing these results, we recognize that the agreement between experimental and theoretical results has been improved for aerosols containing oil. This improvement is much more visible for systems with a high amount of oil. The maximal value of relative difference is now about $60 \%$ (for 2F6/F13 filter) instead of over $200 \%$, but for most filters, it does not exceed $30 \%$. For sole soot aerosol, relative difference is lower for two cases, but for the other two, it's higher. Moreover, in almost every case (except 2F6/F13*, soot+oil_h), CFT modified with SIF underestimates the efficiency of multi-layer filters, which wasn't the case for unmodified CFT (overestimating for aerosols containing a high amount of oil and underestimating for other aerosols).

The CFT does not consider all the effects occurring in the filter during liquid aerosol filtration; therefore, it greatly overestimates the filtration efficiency when oil is present in the system. We introduced the system imperfection factor, which allowed us to describe the deviation of the filter efficiency value from the value determined using CFT in a situation where the assumptions of the latter method are not met. The values of this coefficient allowed us to determine the efficiency of multi-layer filters with reasonable accuracy (much better than pure CFT for aerosols containing a high amount of oil). On this basis, it can be concluded that the SIF coefficient may become a convenient tool for predicting the efficiency of filters with a complex structure.

\subsection{Mass Changes}

Fig. 8(a) presents the changes in the mass of the single-layer filters cause by fibre loading during filtration, and Fig. 8(b) shows the mass change of each layer of the multi-layer filters after filtration. For both the single- and multi-layer filters, the most significant changes occurred utilizing high oil concentration aerosols (oil_h and soot+oil_h), and the smallest change occurred utilising soot aerosol. Even a small addition of oil increases the mass change by one order of magnitude. The filter 2F1 mass change was lower than that of filter F1 for all the oil-containing aerosols. It can be attributed to their high efficiencies (Figs. 4(e) and 4(f)), resulting in most of the aerosols
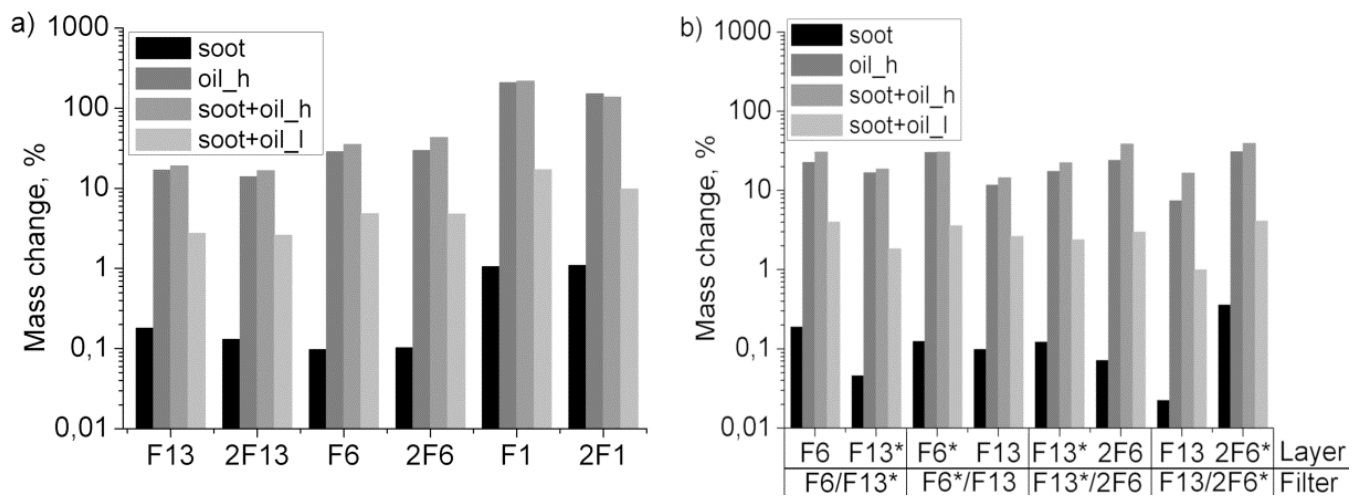

Fig. 8. Mass changes of (a) single- and (b) multi-layer filters utilizing different aerosols. 
Table 5. The relative difference between the calculated and measured change in mass of filters for different aerosols.

\begin{tabular}{|c|c|c|c|c|c|c|c|c|c|c|c|c|}
\hline Aerosol & & ot & & & il_h & & & +oil_h & & & t+oil_l & \\
\hline Filter & $\begin{array}{l}\text { measured } \\
\text { (g) }\end{array}$ & $\begin{array}{l}\text { CFT } \\
\text { (g) }\end{array}$ & $\begin{array}{l}\text { RD } \\
(\%)\end{array}$ & $\begin{array}{l}\text { measured } \\
\text { (g) }\end{array}$ & $\begin{array}{l}\text { CFT } \\
\text { (g) }\end{array}$ & $\begin{array}{l}\text { RD } \\
(\%)\end{array}$ & $\begin{array}{l}\text { measured } \\
(\mathrm{g})\end{array}$ & $\begin{array}{l}\text { CFT } \\
\text { (g) }\end{array}$ & $\begin{array}{l}\text { RD } \\
(\%)\end{array}$ & $\begin{array}{l}\text { measured } \\
\text { (g) }\end{array}$ & $\begin{array}{l}\text { CFT } \\
\text { (g) }\end{array}$ & $\begin{array}{l}\text { RD } \\
\text { (\%) }\end{array}$ \\
\hline F1 & 0.0090 & 0.0111 & 23.4 & 1.1545 & 0.4536 & -60.7 & 1.1649 & 0.5246 & -55.0 & 0.1163 & 0.0787 & -32.3 \\
\hline $2 \mathrm{~F} 1$ & 0.0097 & 0.0112 & 16.3 & 1.1866 & 0.4539 & -61.7 & 1.1980 & 0.5250 & -56.2 & 0.0917 & 0.0792 & -13.6 \\
\hline F6 & 0.0049 & 0.0054 & 8.8 & 0.2722 & 0.3571 & 31.2 & 0.3123 & 0.4242 & 35.8 & 0.0477 & 0.0533 & 11.7 \\
\hline $2 \mathrm{~F} 6$ & 0.0057 & 0.0073 & 27.5 & 0.5097 & 0.3925 & -23.0 & 0.7210 & 0.4601 & -36.2 & 0.0663 & 0.0624 & -5.8 \\
\hline F13 & 0.0024 & 0.0026 & 7.7 & 0.2157 & 0.2120 & -1.7 & 0.2475 & 0.2578 & 4.2 & 0.0304 & 0.0314 & 3.3 \\
\hline $2 \mathrm{~F} 13$ & 0.0047 & 0.0055 & 16.4 & 0.3045 & 0.3549 & 16.6 & 0.3865 & 0.4209 & 8.9 & 0.0535 & 0.0539 & 0.8 \\
\hline
\end{tabular}

CFT: classical filtration theory; RD: relative difference.

being captured at or near the filter surface. The areas located deeper in the high-efficiency filters do not capture a significant number of particles; therefore, the additional volume of these filters is not fully utilised, particularly for filter $2 \mathrm{~F} 1$. The mass changes for the multi-layer filters were larger for the filtration of soot+oil_h aerosol than for oil_h aerosol. The addition of soot to the system increases the available surface area for oil to be captured because the solid soot particles are deposited on the fibres. As shown in Fig. 3(c), soot creates structures that protrude from the liquid film, increasing the surface area, and become coated with oil.

Table 5 shows the relative difference between the calculated and measured change in mass after $64 \mathrm{~min}$ long filtration and simulation. As the results presented are results for single-layer filters, the values were calculated without using SIF. In the case of sole soot aerosol results of our simulations provide good accuracy. In the case of oil_h used method underestimates the mass of the deposits for filters F1, 2F1, 2F6. It can be due to their high efficiency (Fig. 4). Our simulation takes into account particles of sizes from 32.2 to $735.6 \mathrm{~nm}$. Particle size distribution (Fig. 2) shows that the particle concentration for the upper size limit does not reach zero. On this basis, it may be assumed that particles outside of this range are present in the system. The impact of those out-of-size range particles (above $735.6 \mathrm{~nm}$ ) on the mass change is higher in the case of oil_h than soot because of their higher effective density. The effective density of liquid droplets does not change with their diameter. On the contrary, in the case of agglomerates of solid particles, their effective density is lower the bigger their diameter is. The same effect of underestimating the mass can be seen for mixed aerosols. Additionally, the value of the relative difference is lower when the amount of oil in the system is lower.

The final calculated values of effective densities utilized for efficiency calculations are as follows. In the case of sole soot aerosol, the effective density was the one calculated Eq. (B-4) for the mean particle diameter (Table 2) and was $280.28 \mathrm{~kg} \mathrm{~m}^{-3}$. In the case of oil_h, it is the density of the DEHS oil $\left(914.0 \mathrm{~kg} \mathrm{~m}^{-3}\right)$. We assume that droplets have no porosity and are perfect spheres. For the mixed aerosols, the effective density is based on their predicted contributions in the final mass change of the given filter according to soot and oil_h cases. It is because the presence of even a small amount of oil leads to greater change in mass than that associated with sole soot aerosol and it leads to the destruction of the solid structure. The value of effective density for soot+oil_h aerosol was $907.54 \mathrm{~kg} \mathrm{~m}^{-3}$ and for soot+oil_l was $857.24 \mathrm{~kg} \mathrm{~m}^{-3}$.

The method used to calculate the mass of deposits captured by the filters is characterized by reasonably good accuracy. In the case of aerosols containing oil droplets, the accuracy for highefficient filters was influenced by the presence of large-sized oil droplets in the system. However, an accurate quantitative description of the impact of these droplets is difficult to account for due to equipment limitations. The concept of effective density allowed for a good accuracy for sole soot aerosol and mixed aerosols.

\section{CONCLUSIONS}

This study indicates that the presence of oil in the aerosols produces lower filtration efficiency, and the oil concentration in the aerosol affects the initial efficiency and efficiency change during filter loading. 
The addition of oil_I aerosol resulted in a slower increase in or decreased efficiency, although its initial efficiency is similar to that of soot aerosol. Additionally, the pressure drop during filter loading with oil_l aerosol was significantly lower than that of the soot, oil_h, and soot+oil_h aerosols.

The addition of oil_h aerosol resulted in lower initial efficiency and the presence of an obvious maximum efficiency. Once the maximum efficiency was reached, the efficiency decreased, and the higher the overall filter efficiency, the greater the effect.

The proposed system imperfection factor (SIF) can be used to predict the efficiency of multilayer filters.

The calculations carried out for the case of loading filters with particles and droplets have satisfactory accuracy. It can be further improved by including the presence of larger particle sizes in the model, especially in the case of mixed aerosols.

\section{ACKNOWLEDGEMENT}

This publication has been based on the results of a research task carried out within the scope of the fourth stage of the National Programme "Improvement of safety and working conditions" (2017-2019) - within the scope of state services - by the Ministry of Family, Labour and Social Policy. The Central Institute for Labour Protection - National Research Institute is the Programme's main co-ordinator.

\section{APPENDIX A}

The efficiency of the filter was calculated utilizing Eq. (A-1), which is based on the summary efficiency of different filtration mechanisms (A-2). We take into account interception (A-3), diffusion (A-6), inertia (A-9), and interactions between diffusion and interception (A-11).

$E=1-\exp \left(1-\frac{4 \cdot \eta \cdot \alpha \cdot z}{(1-\alpha) \cdot \pi \cdot d_{f}}\right)$

$E$ - filter efficiency, $\eta$ - calculated single fibre efficiency, $\alpha$ - packing density, $Z$ - filter thickness, $d_{f}$ - fibre diameter

$\eta=1-\left(1-\eta_{i n}\right)\left(1-\eta_{d}\right)\left(1-\eta_{i}\right)\left(1-\eta_{d i}\right)$

$\eta_{\text {in }}$ - interception mechanism efficiency, $\eta_{d}$ - diffusion mechanism efficiency, $\eta_{i}$ - inertia mechanism efficiency, $\eta_{d i}$ - efficiency of diffusion and interception interactions

$\eta_{\text {in }}=\frac{1+R}{2 \cdot K u}\left(2 \cdot \ln (1+R)-1+\alpha+\left(\frac{1}{1+R}\right)^{2}\left(1-\frac{\alpha}{2}\right)-\frac{\alpha}{2}(1+R)^{2}\right)$

$R=\frac{d_{p}}{d_{f}}$

$K u=\frac{4 \cdot \alpha-\alpha^{2}-3}{4}-\frac{\ln (\alpha)}{2}$

$R$ - interception parameter, $d_{p}$ - particle diameter, $K u$ - hydrodynamic factor of Kuwabara flow,

$\eta_{d}=1.6\left(\frac{1-\alpha}{K u}\right)^{\frac{1}{3}} \cdot P e^{-\frac{2}{3}}$ 
$P e=\frac{u \cdot d_{f}}{D}$

$D=\frac{k_{B} \cdot T \cdot C}{3 \cdot \pi \cdot \mu \cdot d_{f}}$

$C=1+K n\left(1.142+0.558 \cdot \exp \left(-\frac{0.999}{K n}\right)\right)$

$K n=\frac{\lambda}{d_{f}}$

$P e$ - Peclet number, $u$ - average flow velocity in filter, $D$ - diffusion coefficient, $k_{B}$ - Boltzmann constant, $T$ - temperature, $C$ - Cunningham slip correction factor, $\mu$ - fluid viscosity, $K n$ - Knudsen number, $\lambda$ - mean free path

$\eta_{i}=\left(\frac{S t k}{4 \cdot K u^{2}}\right)\left(\left(29.6-28 \cdot \alpha^{0.62}\right) \cdot R^{2}-27 \cdot R^{2.8}\right)$

$S t k=\frac{\rho_{e} \cdot u \cdot d_{p}^{2}}{\mu \cdot d_{f}}$

Stk - Stokes number, $\rho_{e}$ - effective particle density,

$\eta_{d i}=1.24\left(\frac{R^{\frac{2}{3}}}{(K u \cdot P e)^{0.5}}\right)$

\section{APPENDIX B}

Eq. (B-1) was used to calculate new packing density after the total volume of deposits was captured by the filter during all the time steps up to the current one. New packing density was used to calculate the new average flow velocity in the filter (B-2) and the diameter of the fibre (B-3).

$\alpha=\frac{V_{f}+V_{d}}{V_{t}}$

$u=\frac{u_{0}}{1-\alpha}$

$d_{f}=d_{p}\left(\frac{\alpha}{\alpha_{p}}\right)^{0.5}$

$\alpha$ - packing density, $V_{f}$ - fibres volume, $V_{d}$ - deposits volume, $V_{t}$ - total clean filter volume, $u$ average flow velocity in filter with deposits, $u_{0}$ - average flow velocity in clean filter, $d_{f}$ - calculated fibre diameter, $d_{p}$ - clean fibre diameter, $\alpha_{p}$ - clean filter packing density

The effective density of solid particles was calculated with Eq. (B-4). The value of coefficient $f=$ 2.3 was in accordance with (Maricq and Xu, 2004). The diameter of primary particles $D_{p p}=5 \mathrm{~nm}$ was based on the aerosol generator specification sheet. 
$\rho_{e}=\rho_{0}\left(\frac{D_{p}}{D_{p p}}\right)^{f-3}$

$D_{p p}$ - primary particle diameter, $D_{p}$ - measured particle diameter, $\rho_{0}$ - particle bulk density, $\rho_{e}$ effective particle density, $f$ - fractal dimension

\section{SUPPLEMENTARY MATERIAL}

Supplementary material for this article can be found in the online version at https://doi. org/10.4209/aaqr.210258

\section{REFERENCES}

Agranovski, I.E., Braddock, R.D. (1998a). Filtration of liquid aerosols on nonwettable fibrous filters. AIChE J. 44, 2784-2790. https://doi.org/10.1002/aic.690441219

Agranovski, I.E., Braddock, R.D. (1998b). Filtration of liquid aerosols on wettable fibrous filters. AIChE J. 44, 2775-2783. https://doi.org/10.1002/aic.690441218

Boskovic, L., Agranovski, I., Braddock, R. (2007). Filtration of nanosized particles with different shape on oil coated fibres. J. Aerosol Sci. 38, 1220-1229. https://doi.org/10.1016/j.jaerosci. 2007.09.003

Charvet, A., Thomas, D. (2017). 6 - Filtration of Liquid Aerosols, in: Thomas, D., Charvet, A., Bardin-Monnier, N., Appert-Collin, J.C. (Eds.), Aerosol Filtration, Elsevier, pp. 161-188. https://doi.org/10.1016/B978-1-78548-215-1.50006-8

Contal, P., Simao, J., Thomas, D., Frising, T., Callé, S., Appert-Collin, J.C., Bémer, D. (2004). Clogging of fibre filters by submicron droplets. phenomena and influence of operating conditions. J. Aerosol Sci. 35, 263-278. https://doi.org/10.1016/j.jaerosci.2003.07.003

Frising, T., Gujisaite, V., Thomas, D., Callé, S., Bémer, D., Contal, P., Leclerc, D. (2004). Filtration of solid and liquid aerosol mixtures: Pressure drop evolution and influence of solid/liquid ratio. Filtr. Sep. 41, 37-39. https://doi.org/10.1016/S0015-1882(04)00075-8

Gac, J., Gradoń, L. (2011). Analytical investigation and numerical modeling of collisions between a droplet and a fiber. J. Colloid Interface Sci. 369, 419-425. https://doi.org/10.1016/j.jcis. 2011.12.018

Gac, J., Gradoń, L. (2012). Modeling of axial motion of small droplets deposited on smooth and rough fiber surfaces. Colloids Surf., A 414, 259-266. https://doi.org/10.1016/j.colsurfa.2012. 08.041

Gac, J. (2015). A Simple Numerical model of pressure drop dynamics during the filtration of liquid aerosols on fibrous filters. Sep. Sci. Technol. 50, 2015-2022. https://doi.org/10.1080/ 01496395.2015 .1014496

Gac, J., Jackiewicz-Zagórska, A., Werner, Ł., Jakubiak, S. (2016). Consecutive filtration of solid particles and droplets in fibrous filters. Sep. Purif. Technol. 170, 234-240. https://doi.org/ 10.1016/j.seppur.2016.06.057

Gac, J., Jackiewicz-Zagórska, A., Werner, Ł., Jakubiak, S. (2018). Numerical modeling of solid deposits reorganization during consecutive solid-liquid aerosol filtration: Influence on the dynamics of filtration efficiency. J. Aerosol Sci. 119, 13-21. https://doi.org/10.1016/j.jaerosci. 2018.02.008

González, L.F., Joubert, A., Andrès, Y., Liard, M., Renner, C., Le Coq, L. (2016). Filtration performances of HVAC filters for $\mathrm{PM}_{10}$ and microbial aerosols - Influence of management in a lab-scale air handling unit. Aerosol Sci. Technol. 50, 555-567. https://doi.org/10.1080/ 02786826.2016 .1167833

Kamiński, M., Gac, J.M., Sobiech, P., Kozikowski, P., Jakubiak, S. (2020). Filtration of aerosols containing graphite nanoparticles or their mixture with water droplets on single and multilayer fibrous filters. Sep. Purif. Technol. 237, 116378. https://doi.org/10.1016/j.seppur.2019. 116378

Kralchevsky, P.A., Paunov, V.N., Nagayama, K. (1995). Lateral capillary interaction between 
particles protruding from a spherical liquid layer. J. Fluid Mech. 299, 105-132. https://doi.org/ $10.1017 /$ S0022112095003442

Lee, K.W., Liu, B.Y.H. (1981). Experimental study of aerosol filtration by fibrous filters. Aerosol Sci. Technol. 1, 35-46. https://doi.org/10.1080/02786828208958577

Lee, K.W., Liu, B.Y.H. (1982). Theoretical study of aerosol filtration by fibrous filters. Aerosol Sci. Technol. 1, 147-161. https://doi.org/10.1080/02786828208958584

Lian, G., Thornton, C., Adams, M.J. (1993). A theoretical study of the liquid bridge forces between two rigid spherical bodies. J. Colloid Interface Sci. 161, 138-147. https://doi.org/10.1006/ jcis.1993.1452

Löffler, F. (2004). Air filtration. Von C. N. Davies. Academic Press Inc., London 1973. Chemie Ing. Tech. 46, 364-364. https://doi.org/10.1002/cite.330460823

Maricq, M.M., Xu, N. (2004). The effective density and fractal dimension of soot particles from premixed flames and motor vehicle exhaust. J. Aerosol Sci. 35, 1251-1274. https://doi.org/ 10.1016/j.jaerosci.2004.05.002

Mead-Hunter, R., Bredin, A., King, A.J.C., Larcher, A.V., Becker, T., Mullins, B.J. (2012). The influence of soot nanoparticles on the micro/macro-scale behaviour of coalescing filters. Chem. Eng. Sci. 84, 113-119. https://doi.org/10.1016/j.ces.2012.08.016

Mead-Hunter, R., King, A.J.C., Mullins, B.J. (2014). Aerosol-mist coalescing filters - A review. Sep. Purif. Technol. 133, 484-506. https://doi.org/10.1016/j.seppur.2014.06.057

Müller, T.K., Meyer, J., Thébault, E., Kasper, G. (2014). Impact of an oil coating on particle deposition and dust holding capacity of fibrous filters. Powder Technol. 253, 247-255. https://doi.org/10.1016/j.powtec.2013.11.036

Praphawatvet, T., Peters, J.I., Williams, R.O. (2020). Inhaled nanoparticles-An updated review. Int. J. Pharm. 587, 119671. https://doi.org/10.1016/j.ijpharm.2020.119671

Sutherland, K. (2008). Section 6 - Gas Filtration, in: Sutherland, K. (Ed.), Filters and Filtration Handbook (Fifth Edition), Elsevier, Oxford, pp. 369-450. https://doi.org/10.1016/B978-185617-464-0.00006-7

Thomas, D., Contal, P., Renaudin, V., Penicot, P., Leclerc, D., Vendel, J. (1999). Modelling pressure drop in HEPA filters during dynamic filtration. J. Aerosol Sci. 30, 235-246. https://doi.org/ 10.1016/S0021-8502(98)00036-6 